\title{
Acceptability of HIV oral self-test among truck drivers and youths: a qualitative investigation from Pune, Maharashtra
}

\author{
Amrita Rao ${ }^{1 \dagger}$, Sandip Patil ${ }^{1 \dagger}$, Pranali Pramod Kulkarni ${ }^{2}$, Aheibam Sharmila Devi ${ }^{2}$, Suryakant Shahu Borade ${ }^{2}$,
} Dhammasagar D. Ujagare ${ }^{2}$, Rajatashuvra Adhikary ${ }^{3}$ and Samiran Panda ${ }^{1,4^{*}}$

\begin{abstract}
Background: Ending AIDS by 2030 is a global target, to which India is a signatory. HIV-self-test (HIVST) coupled with counselling and AIDS-care, including antiretroviral therapy, has the potential to achieve this. However, national programs are at varying stages of acceptance of HIVST, as discussions around its introduction spark controversy and debates. HIV-self-test, as yet, is not part of the AIDS control program in India. Against this backdrop, we explored acceptability of an HIV oral self-test (HIVOST) among truckers and young men and women.

Methods: A qualitative investigation with 41 in-depth-interviews and 15 group discussions were conducted in the district of Pune, in the western state of Maharashtra, India. These interactions were built around a prototype HIVOST kit, helped in taking the discussions forward. The software N-vivo (version 11.0) was used to manage the volumes of data generated through the aforementioned process. The study was conducted during June through December, 2019.

Results: While the truckers belonged to the age bracket 21-67 year, the youths were in the age group 18-24 year. 'Ease of doing HIVOST' and 'fear of needle pricks' were the reasons behind acceptance around HIVOST by both the study groups. Truckers felt that HIVOST would encourage one to know one's HIV status and seek help as appropriate. Accuracy of HIVOST result and disposal of the kits following use were concerns of a few. Most of the participants preferred saliva over blood as the specimen of choice. Instructions in local language reportedly would enable test-use by self. The truck drivers preferred undertaking HIVOST at the truckers-friendly 'Khushi clinics' or in the vehicle, while youths preferred the privacy of home. Some of the young men mis-perceived the utility of HIVOST by referring to doing a test on a partner immediately prior to sexual encounter. On the other hand, a few truckers had wrong information on HIV cure.

Conclusions: Overall, the study communities expressed their acceptance towards HIV-self-test. The National AIDS Control Program, India would benefit by drawing upon the findings of the current investigation. Existing myths and misconceptions around HIV test and treatment require program attention.
\end{abstract}

Keywords: HIV self-test, Truckers, Youths, Community voices

\footnotetext{
* Correspondence: director@nariindia.org; pandasamiran@gmail.com

${ }^{+}$Amrita Rao and Sandip Patil contributed equally to this work.

${ }^{1}$ Indian Council of Medical Research- National AIDS Research Institute

(ICMR-NARI), Plot No 73, 'G'Block, MIDC, Bhosari, Pune, Maharashtra 411026,

India

${ }^{4}$ Indian Council of Medical Research Headquarter, V. Ramalingaswami

Bhawan, P.O. Box No. 4911, New Delhi 110029, India

Full list of author information is available at the end of the article
}

C The Author(s). 2021 Open Access This article is licensed under a Creative Commons Attribution 4.0 International License, which permits use, sharing, adaptation, distribution and reproduction in any medium or format, as long as you give appropriate credit to the original author(s) and the source, provide a link to the Creative Commons licence, and indicate if changes were made. The images or other third party material in this article are included in the article's Creative Commons licence, unless indicated otherwise in a credit line to the material. If material is not included in the article's Creative Commons licence and your intended use is not permitted by statutory regulation or exceeds the permitted use, you will need to obtain permission directly from the copyright holder. To view a copy of this licence, visit http://creativecommons.org/licenses/by/4.0/ The Creative Commons Public Domain Dedication waiver (http://creativecommons.org/publicdomain/zero/1.0/) applies to the data made available in this article, unless otherwise stated in a credit line to the data. 


\section{Background}

In India the HIV epidemic is on a decline. However, there are still pockets, where HIV is concentrated among the key population groups namely female sex workers (FSW; 1.56\%), people who inject drugs (PWID; 6.26\%), men having sex with men (MSM; $2.69 \%$ ) and transgender community (TG; 3.14\%) [1]. This was the case even in the early days of the epidemic barring six states (Andhra Pradesh, Tamil Nadu, Maharashtra, Karnataka, Manipur and Nagaland), where a generalized epidemic was witnessed [2]. More than 1\% antenatal clinic (ANC) clinic attending women, were detected with HIV in these states indicating wider spread of the virus beyond most at risk population (MARP) groups [3]. Based on such observations, the targeted intervention (TI) programs were designed, in the long run such an approach has been evaluated to be cost effective [4]. Overall goal of these TI programs in various states was to reduce the vulnerability of the above cited population groups to HIV and other sexually transmitted infections (STIs) and to establish a linkage with HIV care.

The risk of bridge populations such as long distant truckers, migrant workers and other clients of sex workers to HIV was also recognized during the early phase of the AIDS control program in India and interventions were designed to address them as well. The relevance of this approach was underlined by the epidemiologic link, which was established behind the spread of HIV from MARP groups to general population through bridge groups [5]. However, HIV intervention focus, currently directed towards bridge population is not as intense as it used to be earlier. Decreasing HIV prevalence in India in the recent past during 2005 to 2010 might be contributing to such reduced attention [6]. What is of concern though, that the HIV prevalence is refusing to go further down since 2010 [7]. Worth noting against this background is that approximately 69,000 new HIV infections took place in India in 2019 [8]. What is known is that the HIV prevalence among truck drivers is at $0.86 \%$ which is about 3 times higher than the national average adult HIV prevalence [9]. However, age specific HIV prevalence data pertaining to young adults in India is sparse. Considered together, these information not only underline that the residual risks of HIV that exist in the country, but also the need for urgent intervention development. Failing to do so, will negatively impact upon the targets of 95:95:95 to be achieved by 2030 . Such targets require $95 \%$ of the people living with HIV knowing their status, of whom at least 95\% will be put on anti-retroviral therapy (ART) and 95\% of those on ART would achieve undetectable HIV viral load [10].
Vulnerability of truck drivers to HIV emerges from them being away from home and their regular sex partners for long period of time [11]. A study from South India in 2009 reported that truckers with higher income had higher number of sexual partners. Time away from home, urban residence, income and marital status were the factors associated with their high-risk sexual behaviour [12]. A survey from West Bengal revealed that nearly $86 \%$ of the truck drivers had sex with a casual female partner other than their wives in the last 6 months [13].

Keeping such vulnerabilities into consideration, the National AIDS Control Program (NACP) established drop-in-centers specifically at truck halt points [14]. HIV awareness program, testing, treatment facilities for sexually transmitted infections (STIs) and creating an enabling environment constituted the bouquet of services offered from these TI sites [14]. Despite such initiatives, delayed linking of truckers to HIV test and treatment has been noted [15]. As with truckers, vulnerability of adolescents and young adults to HIV in India has also been documented although they did not feature in the MARP groups. Such vulnerabilities of the youths arise either from their patronage to FSWs or exploration in unsafe drug use practices [16]. A study in 2014, among adolescents (15-19 year) in Delhi, the capital city, revealed that more than $45 \%$ of them were exposed to high-risk sexual behaviors [17]. However, studies in the recent times focusing on the vulnerability of truckers and youths to HIV have been few. Noticeably, HIV selftest has the potential to play a key role for these population groups where the threat of infection does not appear obvious to individuals.

The World Health Organization (WHO) defines HIV self-test as a process in which a person collects his or her own specimen (oral fluid or blood) and then performs a test and interprets the result, often in a private setting, either alone or with someone he or she trusts [18]. Different countries are in varying stages of acceptance of HIV self-test. Implementation of HIV self-test is still not without controversy and debate. While, several countries have already introduced or are contemplating introduction of HIV self-test as part of their national strategic plans, India, at present, is yet to do so [19]; studies focussing on acceptability of HIV self-test across different population groups have also been limited. Investigations on women in active or early labour and pregnant women, revealed that the participants preferred undertaking HIV oral self-test over blood [20, 21]. To the best of our knowledge, no studies exist on HIV selftest among truck drivers and youths in India. Against this background, we undertook this investigation to assess the acceptability of HIV oral self-test (HIVOST) among truck drivers and young adults in the country. 


\section{Methods}

The current qualitative investigation was conducted in the district of Pune, Maharashtra, during June through December 2019. Approval from the Institutional Ethics committee (IEC) of the Indian Council of Medical Research-National AIDS Research Institute (ICMRNARI) was obtained before enrolment started. Prior to initiating in-depth-interviews (IDIs) and group discussions (GDs), written informed consent was obtained from each of the participants. INR $150(2.5 \$)$ per person was provided at the end of each session as compensation for travel. While presenting data, we have used pseudonyms in this article to maintain confidentiality of the participants. All the enrolled participants were aged 18 year or above. An HIV oral-self test (HIVOST) kit named Morcheck, a product of Morsef Lifesciences Private Limited and manufactured by Bhat Biotech Private Limited was used as a prototype to facilitate interactions around it.

\section{Gaining access}

Sevadham Trust is a Civil Society Organization (CSO) that works as a TI-partner of the Maharashtra State AIDS Control Society and reaches out to the truckers and migrant workers with HIV intervention. The organization has been working for this cause in Pune over the last two decades. A field assistant, with experience of working earlier with Sevadham Trust, organized IDIs and GDs with truckers from various translocation sites in Pimpri Chinchwad Municipal Corporation (PCMC).

In order to recruit young adults in the study, local youth clubs were contacted. These clubs serve as common platform where youths meet, discuss and plan activities for their future development. The field assistant contacted such youth clubs in various geographical locations to facilitate enrolment of participants with diversity. Additionally, a computer training centre, managed by a private information technology (IT) solution company, was engaged for recruitment of youths. Some of the young women were recruited through self-help groups (SHGs). Other gatekeepers engaged in recruitment of young adults in the current study were community influencers including a primary school teacher. Such recruitment approach helped us in recording different community voices.

Eligible and willing individuals were informed by the field assistants to participate in the current study. The team consisting of a moderator and a note-taker then came to the identified site for conducting IDIs and GDs. Those participating in IDIs were not invited for GDs so that wider range of responses could be obtained; GDs allowed capturing the viewpoints emerging through interaction between the group members, which otherwise would not have been possible through interviewing an individual.

\section{Data collection tools}

The guides and probes used during in-depth- interviews and group discussions were developed by the team at ICMR-NARI based on identified domains requiring exploration and were administered in Marathi and Hindi. These tools underwent trial sessions and were modified for ease of comprehension and correctness of content (Supplementary file 1). The following domains were explored; 'health seeking behaviour', 'prior HIV test experience', 'choice of HIV self-test', 'perceived advantages and disadvantages and apprehensions'. Information was also collected pertaining to the packaging of the kits, presentation, information to go with the kit, how-to-do instructions and preferred kit outlets.

\section{Data collection}

The research team received multiple orientations on research methodology during the study period. These were conducted by the experts from social science background. Checklists prepared for IDI and GD were used by the research team (a moderator and a note-taker dedicated for a specific group of participants), which helped in ensuring consistency [22]. The field assistants ensured that the participants were from the similar socio-cultural background speaking the same native language.

Truckers were initially enrolled from Nigdi transport area, located in the PCMC area of Pune. Following completion of 8 IDIs and 2 GDs among truck drivers at this location, diverge responses ceased to be generated. The research team therefore, decided to conduct data collection at other trans-shipment locations namely, Telco Campus and Moshi. IDIs and GDs were conducted either at the transport offices or in a temple premise identified by the field assistants. A total of 16 in-depthinterviews (IDIs) and 6 groups discussions (GDs) were completed with the truck drivers.

Twenty-five IDIs (12 with young women and 13 with young men) and 9 GDs (4 with young women and 5 with young men) were conducted with the youths. Most of the IDIs and GDs took place either at rented locations or community halls or residence of the participants or project office premise as preferred by the participants. Privacy was maintained at each of these interaction sites; ensuring that no observing bystanders were present during these sessions.

\section{Data analysis}

All interview and group discussion sessions were audio recorded and transcribed exact and translated in English. This approach of using English as a common language was to capture the essence of the responses. Data 
analysts subsequently checked for the quality of translations so that the nuances expressed by participants in local languages were not missed. We incorporated the Guba and Lincoln criteria to check for the quality of research (Table 1) [23]. Acceptability of HIV self-test was explored by carrying out content analysis of both the transcribed and translated responses. A separate codebook was developed for each of the study groups based on the domains explored. Short descriptions of the codes and quotes around them was compiled. This was reviewed periodically and reorganized to identify major or minor themes (categories). The data analysts, with assistance from the research supervisors and other team members helped to resolve the coding discrepancies, if any. Among the other methods, in-vivo coding was used to capture the voices and concerns of the study participants. The field notes prepared by the interviewers before and after their interactions with study participants helped in gathering sufficient reflexivity. $\mathrm{N}$-vivo software (version 11.0) was used to help in organizing the responses and subsequent analysis.

\section{Results}

\section{Profile of the participants - truckers}

While some of the truckers were engaged in longdistance travel across the country, movements of others were limited to the State of Maharashtra. All the IDI participants among truckers were married and belonged to the age group 21 to 67 year. While one of them was a science graduate, six had primary school level education, 4 had studied till 10th standard and the remaining 5 had completed 12th standard of school education. Each of the interviews lasted for $50-85 \mathrm{~min}$. Each focus group with the truckers had 5 to 6 participants and most of the discussions lasted about an hour; the longest taking $1 \mathrm{~h}$ and $40 \mathrm{~min}$. The discussants belonged to the age group 21-55 year; most were married and the level of school education varied from 3 rd to 12 th standard.

\section{Profile of the participants - youths}

All the participants were in the age group of 18 to 24 year. Majority of the women interviewees had secondary school education and some completed graduation. Among the 12 young women interviewees; only 4 were married and homemakers. Among the unmarried women, most were studying, one was at home and only one of them was involved with income generating activity.

All the participating young men in IDIs and GDs were unmarried. Of the 13 young men enrolled for IDI, 3 did not have school education beyond higher secondary (12th standard) and four had completed graduation in subjects such as arts, science and engineering; five others were continuing graduate studies. In-depth interviews with women lasted for $50 \mathrm{~min}$ to $1 \mathrm{~h}$, while interviews with men lasted for 30-50 min.

Four GDs were held with young women (3 groups constituted by unmarried women and 1 by married women); each involving 5 to 6 participants. Most of the women were studying;10th standard to pursuing a degree at college; 2 of them were involved with income generation activities. Each of these GDs lasted for about $45 \mathrm{~min}$.

Each of the five GDs with young men lasted for about $65 \mathrm{~min}$ and each involved 4 to 7 participants. Their level of school education varied from 10th standard to graduation. Members of only one group were involved with income generating activities, while the rest were all students.

\section{Prior HIV test experience}

Majority of the truckers had undergone HIV test; some at 'Khushi clinics' - an initiative by the Transport Corporation of India Foundation aiming to reduce spread of HIV and other STIs among long distant truck drivers. Others took HIV test at government hospitals. While overall experience in the former setting was positive, hurdles were faced by some in government settings. 'Apprehension of getting identified while seeking HIV test from public health facilities' and 'spread of such information within the groups of truckers' were associated concerns.

"He is afraid of going to hospital. What he says individuals will see him - that's why, need not go to hospital - that's why he does not come in front" - Igat, 45 year (TRUCKER 11)

All married women IDI-participants (during pregnancy) and 2 unmarried women had HIV test experience. A few women members in GDs had prior HIV test experiences as well. Contrastingly, among the male participants, only one interviewee and 2 group discussants reported experience of prior HIV test.

Difficulties faced by women during HIV test were of varying nature such as pain associated with needle prick during blood drawing, panic associated with the volume of blood drawn, fear of unknown as HIV test was undertaken for the first time and the hassle of detour from one department to another in the hospital. Negative attitude of some of the health care providers was another concern.

"That you know - take blood from finger, take blood from vein - I had much trouble - take a lot of blood - they remove blood until tears come in eyes ... ... I had never taken HIV test before delivery - but during pregnancy they took a blood sample ... but then I was scared a bit" - Suna, 24 year (YOUNG WOMAN 02) 
Table 1 Strategies adopted to ensure quality in the present HIVOST acceptability study

\begin{tabular}{|c|c|c|c|}
\hline $\begin{array}{l}\text { Rigour } \\
\text { Criteria }^{a}\end{array}$ & Purpose & Original Strategies & $\begin{array}{l}\text { Strategies applied in our study to achieve } \\
\text { rigour }\end{array}$ \\
\hline \multirow[t]{5}{*}{ Credibility } & \multirow[t]{5}{*}{$\begin{array}{l}\text { To establish confidence that the results (from } \\
\text { the perspective of the participants) are true, } \\
\text { credible and believable. }\end{array}$} & $\begin{array}{l}\text { - Field assistants chosen from the } \\
\text { local community played a crucial } \\
\text { role in engaging the participants for } \\
\text { the IDIs and FGDs }\end{array}$ & $\begin{array}{l}\text { - Prior experience of the field assistant in } \\
\text { working with truckers and self-help groups } \\
\text { helped us in conducting quality IDIs and } \\
\text { FGDs against a backdrop of trust and } \\
\text { rapport. }\end{array}$ \\
\hline & & - Interviewing process and techniques & $\begin{array}{l}\text { - Research team members conversant with } \\
\text { the local socio-cultural context used the } \\
\text { guides and probes in mock sessions and re- } \\
\text { ceived inputs for modifications as needed. } \\
\text { Place of interactions between the researchers } \\
\text { and participants were also chosen as per } \\
\text { participants' convenience ensuring privacy } \\
\text { and confidentiality }\end{array}$ \\
\hline & & - Establishing investigators' authority & $\begin{array}{l}\text { - The research team received multiple } \\
\text { exposures on research methodology during } \\
\text { the study period. Orientation programs were } \\
\text { also conducted by experts from social } \\
\text { science background so that everyone was } \\
\text { well versed with the methodology applied }\end{array}$ \\
\hline & & $\begin{array}{l}\text { - Collection of referential adequacy } \\
\text { materials }\end{array}$ & $\begin{array}{l}\text { - The field assistant and interviewers filled the } \\
\text { field notes and debriefing forms at the end } \\
\text { of each session. This helped the entire team } \\
\text { to conduct ongoing and final analysis, and } \\
\text { adopt inductive investigation approach. }\end{array}$ \\
\hline & & - Peer debriefing & $\begin{array}{l}\text { - Debriefing sessions were held with the } \\
\text { research supervisor and colleagues; which } \\
\text { helped in clarifying doubts and resolving } \\
\text { conflicts around coding (if any) }\end{array}$ \\
\hline \multirow[t]{3}{*}{ Dependability } & \multirow{3}{*}{$\begin{array}{l}\text { To ensure the findings of this qualitative } \\
\text { inquiry are repeatable if the inquiry occurred } \\
\text { within the same cohort of participants, } \\
\text { coders and context. }\end{array}$} & $\begin{array}{l}\text { - Rich description of the study } \\
\text { methods }\end{array}$ & $\begin{array}{l}\text { - Detailed draft of the implementation plan is } \\
\text { available. }\end{array}$ \\
\hline & & - Establishing an audit trail & $\begin{array}{l}\text { - Information obtained from earlier cohorts of } \\
\text { participants (truckers in particular) were } \\
\text { contrasted against the latter cohorts to } \\
\text { examine if saturation point was being } \\
\text { reached through repeatability and also to } \\
\text { record rare points of views. }\end{array}$ \\
\hline & & - Stepwise replication of the data & $\begin{array}{l}\text { - While truckers were recruited from three } \\
\text { different halt points, responses were } \\
\text { contrasted to examine replication. Youths } \\
\text { recruited from different clubs or locations } \\
\text { similarity offered opportunity for such } \\
\text { comparisons. }\end{array}$ \\
\hline \multirow[t]{2}{*}{ Confirmability } & \multirow{2}{*}{$\begin{array}{l}\text { To extend the confidence that the results } \\
\text { would be confirmed or corroborated by } \\
\text { other researchers. }\end{array}$} & - Reflexivity & $\begin{array}{l}\text { - We implemented reflexive notes and also } \\
\text { held weekly investigators' meetings. }\end{array}$ \\
\hline & & - Triangulation & $\begin{array}{l}\text { - Several triangulation techniques (IDIs vs GDs, } \\
\text { data sources such as transcript, field notes } \\
\text { and debriefing notes) were used in the } \\
\text { current investigation to obtain } \\
\text { comprehensive views around the domains } \\
\text { explored }\end{array}$ \\
\hline \multirow[t]{2}{*}{ Transferability } & \multirow[t]{2}{*}{$\begin{array}{l}\text { To extend the degree to which the results } \\
\text { can be generalized or transferred to other } \\
\text { contexts or settings. }\end{array}$} & $\begin{array}{l}\text { - Purposeful and convenient sampling } \\
\text { to form a nominated sample }\end{array}$ & $\begin{array}{l}\text { - We used different data collection } \\
\text { approaches to capture voices from the } \\
\text { communities including common and rare } \\
\text { point of views, with potential for their } \\
\text { transferability to similar socio-cultural } \\
\text { settings }\end{array}$ \\
\hline & & - Data saturation & $\begin{array}{l}\text {-In order to identify if data saturation was } \\
\text { reached, we carried out } 8 \text { to } 10 \text { or more } \\
\text { interactions and also had on-going analysis. }\end{array}$ \\
\hline
\end{tabular}




\section{Myths and misconceptions around HIV}

Interviews unravelled a range of mis-information truckers had on HIV transmission and treatment. Reportedly, a newspaper in Osmanabad (an administrative district in Marathwada region in the state of Maharashtra) published a story on an HIV infected individual getting cured following consumption of pesticides used on cotton plants. An incident of HIV cure by snake venom was narrated by another trucker. None of the youths reported any such information around HIV.

\section{Advantages of HIV oral self- test}

Most of the truck drivers felt that HIVOST would benefit them and a few of them opined that availability of such a kit would lead to increased detection of infection and further linkages with anti-HIV treatment. Vulnerability of the truck drivers to HIV and other diseases were highlighted during these sessions, and 'confidentiality' as well as 'convenience of doing the test by self', were perceived as merits of HIV self-test.

"The advantage is that if we have any information then we will implement ... . If we have to walk on the road and we know the direction of the road then only we will reach ... if we do not know the direction of the road then we will get lost ... that is why I have interest in it"

- Duey, 61 year (TRUCKER 04)

"... as many drivers are there, they all will benefit ... actually, means driver line is such that people have to go outside for work ... all these diseases happen mostly to driver people ... mainly drivers are targeted ... It (HIV self-test) will be useful for us ... it will be very useful for those in this field"

- Suaj, 57 year (TRUCKER 14)

HIV oral self-test (HIVOST) concept was greeted by most of the young adults during IDIs and GDs. Long queue, fear of getting identified by somebody known, stare from people, and fear of breach of confidentiality at HIV testing centres were the reasons cited by young men welcoming HIVOST. Some of them even indicated that HIVOST would enable one to take the test at home and highlighted the ease of using it.

"We can easily take saliva - similarly blood we cannot draw"

- A young woman from group discussion

(GD YOUNG WOMAN 03)

"Because we can do it easily ... because saliva is in our mouth, we can easily do the test, blood is in our body ... we have to draw it. And some people are scared of blood that is why saliva is comfortable"

- Gash, 18 year (YOUNG MAN 08)

Advantage of using oral saliva-based test in children was highlighted by a married woman, while another woman elaborated upon hesitation to discuss HIV even with a doctor and highlighted the advantage of HIV selftest in such context. Women participants, without prior HIV test experience, reflected upon their social interactions and highlighted how HIVOST could be helpful. Situations cited by them encompassed young boys and girls contemplating sex, pre-marital HIV test and familial level disputes. Some of the young men mentioned that HIV self-test should be deployed in brothels and lodges before engaging in sex (wrongful expectation).

"If - I get an easy option (choice) at home itself, then I will not waste (spend) my time by going to the lab - If facilities are provided, then definitely there is no harm in taking them - why to waste our time while going outside, waiting in queue for reports" -Shpa, 23 year, (YOUNG WOMAN 04)

"I can do the self-test and it would be confidential. I can directly discuss with the doctor - there is no need to tell anyone, or no need to write anywhere"

-Psad, 21 year, (YOUNG MAN 07)

\section{Specimen of choice}

Saliva was preferred over blood by both the truck drivers and youths. 'Ease of using saliva as test specimen', 'lack of knowledge on how to draw blood', 'quick results', 'ability to do the test by self' and 'fear associated with needle prick' were cited advantages. Young women preferred HIVOST compared with the traditional blood-based HIV test conducted in laboratories or hospitals; a few of them did not express any preference for clinical specimen, and very few preferred blood over saliva.

"There is no need to tell anyone - we ourselves can come to know if we have HIV or not"-Gan, 28 year (TRUCKER 07)

In two of the group discussions with young men, rare viewpoints such as presence of HIV in the blood and unknown accuracy of saliva-based test were put forth as justification to choose blood over saliva. The other rare justifications were blood being internal (core) element of the body would capture the presence of the disease at an early stage and possibility of using the blood specimen taken for HIV test to conduct other investigations such as CD4 count. 
"If doing from blood then you can know HIV, but you can also know CD4 count ... .or other things can be checked"

- Deti , 18 year (YOUNG WOMAN 03)

\section{Apprehensions around HIVOST}

We grouped potential harms as perceived by the participants in three categories, a) societal, b) individual and c) environmental.

\section{Societal harm}

None of the youths during IDIs or GDs flagged societal harm as an issue that could arise following introduction of HIVOST. A few though talked about judgmental attitude of the society towards HIV.

"Means, as now what I said as the logo is very famous (HIV logo in the form of a red ribbon) because where ever HIV word comes ... at that place, this ribbon comes ..., so basically this logo belongs to this (HIV). So may be someone notices this, so the person in front may quickly start to think that the person has done something. So, he needs this product. Sometime people do not think, that why are you doing this - Means when a person sees something in front of him, so he quickly starts to think about it"

- Shpa, 23year (YOUNG WOMAN 04)

"If we share about it with friends that I have such and such problem... even he is very close to us, he may have friends to whom he can tell ... that your HIV test result is so and so... then people start looking at you in a different way. And due to this fear, one cannot talk about it (test) or one avoids to take this test"

- Roan, 21 year (YOUNG MAN 01)

\section{Individual harm}

Possibility of getting into depression leading to selfharm or reluctance to seeking treatment following positive HIV result were apprehensions raised by some of the youths (both men and women).

"That person will be mentally disturbed - he will not understand what to do. If some person is too emotional then he will do something to himself means suicide etc. Some person will go into depression (after HIV OST positive result)"

- Prti, 19 year (YOUNG WOMAN 09).

Anxiety related to HIV positive test result was obvious through the responses of a few truckers; one of the truckers viewed HIV positive test result as something like the end of the world. These were not specific to HIVOST though.
"They will be demoralized as soon as they get to know ... first and foremost they would get demoralized. Sometimes, they would say that they don't even want the tablets ... since now, I have got the disease ... I don't need to take the tablets ... it's better to die ... if society comes to know about it tomorrow that I have got this ... then who do I face ... what would I tell people at home"

-Isa, 47 year (TRUCKER 05)

Young men also brought up issues such as 'leakage of information' and 'forced testing during marital negotiation'. Very few participants expressed that prank could be played with HIV self-test. Accuracy of the HIV selftest result was another concern raised by some of the young men and women

“... ... if I want to get someone into trouble - if I want to demoralize someone I will do someone's HIV test ... one who is HIV positive and push it on you ... and say you are HIV positive... then in your mind you'll have doubts about HIV - you will be demoralized a little bit - the freshness that you had or that you were so free - you will not remain that free - in your mind there will be continuous worry"

- Psad, 21year (YOUNG MAN 07)

"I don't know about its accuracy - It's new test right. You will have to prove it first then only you can bring it in market. Everyone should be aware of its accuracy"

- A young man from a group discussion

(GD YOUNG MAN 01)

A rare point of view was raised pertaining to the fluid (reagent) in the tube that comes with the HIVOST-kit, by a truck driver from Punjab. He mentioned that the fluid could be used for injections by drug users while, a young male interviewee assumed that the fluid might contain acid and could be poured on to someone to cause harm.

\section{Environmental harm}

A few youths were concerned about safe disposal of the test kits, failing which could result in environmental pollution. A few truckers were also concerned about disposal of test kits vis-à-vis environmental pollution. Inappropriately disposed self-test kits in the garbage was seen by another truck driver as an issue concerning risk to others' health.

"'Little bit it will affect the environment, and also pollution will take place - because we throw it in the garbage - basically there is not one as such - if 
you go to their work place and see that they set it on fire, and from that air pollution is caused,"

-Shpa, 23 year (YOUNG WOMAN 04)

"If this test comes in the market then everyone will know about it - we can't throw it there. Someone will see it while emptying the garbage there or while throwing the garbage if someone sees it-they will come to know"

-Isa, 47 year, (TRUCKER 05)

\section{Kit considerations}

Participants were shown various components of the HIV self-test kit and the package insert with pictorial diagrams on 'how-to-do' steps. The following domains pertaining to kit consideration were explored (Table 2); a) packaging, b) instruction leaflet, c) kit outlet, d) cost consideration, and e) information to go with the kit.

A few youths expressed that the kit should have been smaller in size for convenience of carriage. Most of the participants wished to see HIV symbol (red ribbon) on the kit. It was further suggested that the instructions should be presented in local language for easy comprehension.

Most of the youths considered taking HIVOST in the privacy of their bedroom or other places home as appropriate, while truckers preferred taking it at 'Khushi clinics' or in the vehicle. Easy availability of the kits at various halt points such as 'toll nakas' and 'dhabas', were the felt needs of the truck drivers. Youths recommended making kits available at schools and colleges. Wastage and mischievous use of kits, when made available free of cost, were the apprehensions of the youths and truck drivers. The suggested price tag for a kit ranged from INR 10 to INR 400 .

\section{Discussion}

This qualitative investigation explored issues around HIV self-test from the perspectives of truckers and youths; two vulnerable population groups in India. The country is committed to the global goal of 'ending AIDS by 2030' [24] and the National AIDS Control Program (NACP) in India is working towards it. However, the major challenge is to encourage people to know their own HIV status, could be linked with anti-retroviral treatment facilities. A systematic review of 23 studies by Figueroa et al. reported high acceptability of HIV selftests among key population groups such as MSM, FSW, TG, PWID and people in prison [25]. The issue nonetheless has not been studied adequately among certain vulnerable populations such as youths and truck drivers. The present investigation, being qualitative in nature and examining acceptability of HIVOST, therefore stands out as an important initiative.

Both truckers and youths, during our inquiry, welcomed HIV self-test. Truck drivers from Hyderabad in Andhra Pradesh accepted oral HIV self-test as an innovative HIV intervention approach. Most of the truck drivers were even willing to undertake HIV self-test

Table 2 Kit considerations

\begin{tabular}{|c|c|}
\hline DOMAINS & QUOTATIONS \\
\hline PACKAGING & $\begin{array}{l}\text { "Kit looks a little big, sir ... It should be a little small ... one that can easily fit in the pocket" } \\
\text {-A truck driver from group discussion } \\
\text { (GD- TRUCKER 04) } \\
\text { "Name (what for) should be written only. -it should be known only" } \\
\text { - Prik, } 23 \text { year (YOUNG MAN 11) }\end{array}$ \\
\hline \multirow[t]{2}{*}{$\begin{array}{l}\text { HOW TO DO IT - } \\
\text { INFORMATION }\end{array}$} & $\begin{array}{l}\text { "I would like to know if someone explains. But if pictures are displayed in a different way then it's okay. If it is shown in } \\
\text { hospitals how to do it, it would be much better. If explained in local Marathi language then it would be of benefit" } \\
\text { - Igat, } 45 \text { year (TRUCKER 11) }\end{array}$ \\
\hline & $\begin{array}{l}\text { "As you can see in "Save the girl child and educate her (Beti bachao, Beti Padhao) ... .on the television ... in the same way } \\
\text { it (HIV self-test) can also happen ... it should happen for this (HIVOST). That means every home...it should be known that } \\
\text { there is such kind of thing is there. While sitting at home you can check / test. For this more advertisement should be made" } \\
\text { - Shpa, } 23 \text { year (YOUNG WOMAN 04) }\end{array}$ \\
\hline \multirow[t]{2}{*}{ ACCESS POINTS } & $\begin{array}{l}\text { "It should be available everywhere - at Dhaba, at Pan Stall. It should be made available in the hospitals and even at your } \\
\text { office - your department - It should be available in all these places" } \\
\text { - Diar, } 43 \text { year, (TRUCKER 12) }\end{array}$ \\
\hline & $\begin{array}{l}\text { "Even at schools and colleges - as youths must be aware - It is very good for young people. They should be aware of such } \\
\text { things" } \\
\text { - Prla, } 23 \text { year, (YOUNG WOMAN 11) }\end{array}$ \\
\hline \multirow[t]{2}{*}{$\operatorname{cosT}$} & $\begin{array}{l}\text { "If it is kept for free then it would not be so much - people would not understand its importance - so at least some price } \\
\text { should be fixed" } \\
\text { - Nene, } 28 \text { year (TRUCKER 07) }\end{array}$ \\
\hline & $\begin{array}{l}\text { "If free, the one who is in need will take it and the one who does not need it will also take it." } \\
\text {-A young boy from group discussion } \\
\text { (GD-YOUNG MAN 03) }\end{array}$ \\
\hline
\end{tabular}


while available [26]. Studies focusing on HIV self-test among youths in India are sparse. A qualitative study from Malawi and Zimbabwe among 16- to 25-year-old reveals that HIV self-test was preferred provided it was available free or at low cost [27].

In the current investigation, saliva-based HIV self-test was preferred over blood. The advantages cited were freedom from fear of needles and ability to do the test by self. A study conducted among in-patients and outpatients at the rural teaching hospital in Sevagram, Maharashtra recorded preference for oral-fluid over the blood-based HIV self-test [28]. However, scepticism on accuracy of HIVOST and the need for establishing linkages with the post-test counselling services were expressed by some of the participants in the current investigation as was noted by other researchers [29-31].

The present investigation revealed the discomfort of the participants to go to government hospitals for HIV testing; loss of privacy and apprehension about breach of confidentiality were the concerns. Contrastingly, truckers undergoing HIV test at Khushi clinics, located at trans-shipment sites, found the arrangement user-friendly. Woodford et al. elaborated upon the barriers to HIV testing at individual, interpersonal, socio-structural and health care levels among the MARP groups in Chennai, Tamil Nadu in India. Stigma associated, not only with the disease, but also HIV-test per se was cited as hindrance to access test services. Participants in this study also feared discrimination from the community and society, which delayed their access to HIV-tests. Timings, long queue, and extended waiting period were other deterrents for accessing these facilities [32], which were similar to our findings. Noticeably, most of the youths except young married women (who got tested for HIV during ante-natal check-up), in our study did not have a prior HIV test experience.

The participants in the current study reported some apprehensions around HIVOST such as accuracy of the results, disposal of kits, and self-harm. These findings were similar to the concerns raised by the MSM and TG populations around in Pune, Maharashtra in India [33].

Truckers, in the current investigation, preferred obtaining instructions on HIVOST through live demonstration or video clippings and youths wished to have them in local languages. Some of the youths erroneously felt that HIVOST could be used as a diagnostic test rather than a screening tool. On the other hand, the myths and mis-conceptions around HIV treatment were limited to only a few of the truckers. Given the practice of truckers spending time in groups at halt points, and wrong information could spread through words of mouth, interventions to dispel them appeared important. Studies published nearly a decade ago, similarly highlighted misconceptions prevailing among truck drivers, on the mode of transmission [34]. It was intriguing to note that in a study focussing on youths recorded beliefs that HIV could be cured and a vaccine was available for HIV [35].

During current inquiry, the truck drivers wished that they could get HIV self-test kits at common halt points; reportedly, they would prefer using them either at the trucker-friendly-clinics (such as Khushi) or in the vehicle. A study from Kenya, among truck drivers, recruited from wellness clinics, highlighted that those, who never undertook an HIV test would prefer HIV self-test [36]. Young adults in the current study mentioned that they would prefer taking HIV self-test in privacy of their homes. This was similar to the findings emerging from South Africa. In Mozambique, adolescents preferred taking the test at youth-friendly clinics [37-39].

HIV self-test has been in discussion for more than a decade [40]. However, a number of countries are still weighing the pros and cons of introducing HIV self-test in their policies. India is still debating its inclusion in the program. We hope that the evidence generated across different population groups, as with the current investigation, assist the national program in implementation of HIV self-test.

\section{Limitations}

This is a small-scale acceptability study that was conducted among truckers and youths in the district of Pune, representing only a sub-section of the study population. We enrolled truckers halting at the translocation points, which were selected as recruitment sites. However, such recruitment strategy could not include the truckers who were not accessing these HIV outreach program sites. Similarly, the young people, who did not attend the venues used for recruitment, could not be included. Other studies from different geographical and socio-cultural settings would help in obtaining diverse views and overcoming the aforementioned limitations.

\section{Conclusion}

We conclude that HIV self-test will have acceptability among truckers and young adults in Indian setting. The participants expressed their enthusiasm to use such a test as the results could be quickly obtained and one could do the test on his or her own. However, it will be necessary to address existing apprehensions around HIV self-test and pair such initiatives with interactive strategies to mitigate misconceptions about HIV test and treatment. Community voices captured through the current qualitative investigation underline the necessity of such programmatic initiatives.

\section{Abbreviations}

CSO: Civil Society Organization; FSW: Female Sex workers; GD: Group Discussion; HIV: Human Immunodeficiency Virus; HIVST: HIV self-test; HIVOST: HIV oral self-test; IEC : Institutional Ethics Committee; ICMR- 
NARI: Indian Council of Medical Research-National AIDS Research Institute; IDI: In-depth-interviews; IT: Information Technology; MARP: Most at risk population; MSM: men having sex with men; NACP: National AIDS Control Program; PCMC: Pimpri Chinchwad Municipal Corporation; PLHIV: People Living with Human Immuno-deficiency; SHG: Self Help Group; STI: Sexually Transmitted Infections; TI: Targeted Intervention; TR: Truckers; UNAIDS: Joint United Nations Program on HIV/AIDS; WHO: World Health Organization; YB: Young Boys; YG: Young Girls

\section{Supplementary Information}

The online version contains supplementary material available at https://doi. org/10.1186/s12889-021-11963-7.

Additional file 1. Guides for In-depth Interview and Group Discussion.

\section{Acknowledgements}

Dr. SM Shahabuddin, Technical Officer, ICMR-NARI assisted in literature search and referencing work. The software N-vivo (version11) was procured from the World Health Organization (WHO) grant. Morsef Life Sciences LPP supplied a consignment of oral HIV self-test Morcheck to ICMR-NARI for a performance evaluation from which, 5 randomly drawn kits were used for demonstration in the present investigation and to build interactions of the participants during group discussions and reflections of the participants during IDIs.

\section{Authors' contributions}

AR: Investigation, analysis, validation \& writing draft; SP1: Investigation, analysis, validation \& writing draft, PPK: Analysis \& quality check of the interviews; ASD: Analysis \& quality check of the interviews; SSB: Investigation \& validation; DDU: Investigation \& validation; RA: Supervision \& project administration; SP2: Conceptualization, supervision, project administration, analysis \& writing draft. All authors read and approved the manuscript.

\section{Funding}

This project was funded by World Health Organization grant (Technical Service Agreement: 2018/868515). The funding body did not play a role in study design, data collection, analysis, interpretation and writing of the manuscript.

\section{Availability of data and materials}

Due to the sensitive nature of the questions asked in this study, the survey respondents were assured that the raw data will remain confidential and will not be shared. The data will not be available on public domain. However, if a valid request is made to the corresponding author, the data will be made available through official email communication.

\section{Declarations}

Ethics approval and consent to participate

This study was approved by Institutional Ethics Committee of ICMR-NARI (NARI /EC/ Approval /2019/259 dated 8/3/2019).

This study was performed in line with the principles of the Declaration of Helsinki. Written informed consent was obtained from all the participants.

\section{Consent for publication}

Not applicable.

\section{Competing interests}

The authors declare that there is no conflict of interest.

\section{Author details}

${ }^{1}$ Indian Council of Medical Research- National AIDS Research Institute (ICMR-NARI), Plot No 73, 'G'Block, MIDC, Bhosari, Pune, Maharashtra 411026, India. ${ }^{2}$ WHO supported Acceptability project of Indian Council of Medical Research- National AIDS Research Institute (ICMR-NARI), Plot No 73, 'G'Block, MIDC, Bhosari, Pune, Maharashtra 411026, India. ${ }^{3}$ World Health Organization -India Country Office, R K Khanna Tennis Stadium, New Delhi 110029, India. ${ }^{4}$ Indian Council of Medical Research Headquarter, V. Ramalingaswami Bhawan, P.O. Box No. 4911, New Delhi 110029, India.
Received: 29 April 2021 Accepted: 11 October 2021

Published online: 24 October 2021

\section{References}

1. National AIDS Control Organization. National Strategic Plan for HIV/AIDS and STI 2017-2024: paving way for an AIDS free India. New Delhi: Ministry of Health and Family Welfare, Government of India; 2017. http://naco.gov.in/ sites/default/files/Paving\%20the\%20Way\%20for\%20an\%20AIDS\%201512201 7.pdf. Accessed 19 Oct 2021

2. Dasgupta PR, Jain MK, John TJ. Government response to HIV/AIDS in India. AIDS. 1994:8(Suppl 2):S83-90 PMID: 7857572.

3. Ramachandran P. ICMR's tryst with HIV epidemic in India: 1986-1991. Indian J Med Res. 2012;136(1):13-21.

4. Prinja S, Bahuguna P, Rudra S, Gupta I, Kaur M, Mehendale SM, et al. Cost effectiveness of targeted HIV prevention interventions for female sex workers in India. Sex Transm Infect. 2011;87(4):354-61. https://doi.org/10.113 6/sti.2010.047829 PMID: 21447514.

5. Parkhurst JO. Structural approaches for prevention of sexually transmitted HIV in general populations: definitions and an operational approach. J Int AIDS Soc. 2014;17(1):19052. Published 2014 Sep 8. https://doi.org/10.7448/IA S.17.1.19052.

6. National AIDS Control Organization. Mid-term appraisal of National AIDS control program: Phase IV: technical report. New Delhi: Ministry of Health and Family Welfare, Government of India; 2016. http://www.naco.gov.in/ sites/default/files/Report\%20of\%20the\%20MTA\%20of\%20NACP\%20IV\%20-\%2 OAugust\%202016.pdf. Accessed 19 Oct 2021.

7. National AIDS Control Organization. HIV Estimations Report. Technical report, 2018. New Delhi: Ministry of Health and Family Welfare, Government of India; 2017.

8. National AIDS Control Organization \& ICMR-National Institute of Medical Statistics. HIV Estimations Report. Technical report, 2020. New Delhi: Ministry of Health and Family Welfare Government of India; 2019.

9. National AIDS Control Organization, Ministry of Health and Family Welfare, Government of India. Sankalak: Status of National AIDS Response, 2017 New Delhi.

10. Fast-Track - Ending the AIDS epidemic by 2030. UNAIDS. https://www.una ids.org/sites/default/files/media_asset/JC2686_WAD2014report_en.pdf. Accessed on 11 March 2021.

11. Pandey A, Mishra RM, Sahu D, Benara SK, Sengupta U, Paranjape RS, et al. Heading towards the Safer Highways: An assessment of the Avahan prevention programme among long distance truck drivers in India. BMC Public Health. 2011;11(6):S15.

12. Dude A, Orungati A, Kumar V, Yelandi V, Schneider J. HIV infection, Genital Symptoms and Sexual Risk Behavior among Indian Truck Drivers from a Large Transportation Company in South India. J Glob Infect Dis. 2009;1(1): 21-8. https://doi.org/10.4103/0974-777X.52977.

13. Biswas S, Chakraborty D, Ghosh P, Kumar P, Adhikary R, Saha MK. HIV Risk profile and its socio-demographic correlates among long-distance truckers in West Bengal, India: Evidence from national HIV sentinel surveillance 2017. Indian J Public Health. 2020;64:S8-14.

14. National AIDS Control Organization. Targeted Intervention under NACP III -Operational Guidelines Volume 2 Migrants and Truckers. New Delhi: Ministry of Health \& Family Welfare; 2007. http://www.naco.gov.in/sites/defa ult/files/NACO-Targeted_Interventions_Under_NACP_III_-_Volume_II_-_ Migrants_and_Truckers.pdf. Accesssed 19 Oct 2021.

15. Sharma V, Saggurti N, Bharat S. Health care coverage among long-distance truckers in India: an evaluation based on the Tanahashi model. HIV AIDS (Auckl). 2015;7:83-94. https://doi.org/10.2147/HIV.S76416 PMID: 25848319; PMCID: PMC4376185.

16. Nath A. HIV/AIDS and Indian youth - a review of the literature (1980-2008). SAHARA J. 2009;6(1):2-8. https://doi.org/10.1080/17290376.2009.9724923.

17. Mehra B, Bhalla P, Rawat D. Indian adolescents and human immunodeficiency virus: a pilot study from Delhi. J Family Med Prim Care. 2016;5(1):187-9. https://doi.org/10.4103/2249-4863.184665.

18. World Health Organization. Guidelines on HIV self-testing and partner notification: Supplement to consolidated guidelines on HIV testing services. Geneva: WHO; 2016. Accessed 11 March 2021

19. Rao A. HIV self-test during the time of COVID-19, India. Indian J Med Res. 2020;152(1):164-7. https://doi.org/10.4103/ijmr.IJMR_2521_20.

20. Pai NP, Barick R, Tulsky JP, Shivkumar PV, Cohan D, Kalantri S, et al. Impact of round the clock, rapid oral fluid HIV testing of women in labor in rural 
India. PLoS Med. 2008;5(5):e92. https://doi.org/10.1371/journal.pmed. 0050092.

21. Sarkar A, Mburu G, Shivkumar PV, Sharma P, Campbell F, Behera J, et al. Feasibility of supervised self-testing using an oral fluid-based HIV rapid testing method: a cross-sectional, mixed method study among pregnant women in rural India. J Int AIDS Soc. 2016;19(1):20993. https://doi.org/10.744 8/IAS.19.1.20993

22. Mack N, Woodsong C, Macqueen KM, Guest G, Namey E Qualitative Research Methods: a data collectors's field guide. Family Health International; 2005. https://www.researchgate.net/publication/215666086_ Qualitative_Research_Methods_A_Data_Collector's_Field_Guide/ comments\#fullTextFileContent. Accessed 19 Oct 2021.

23. Linclon YS, Guba EG. But is it rigorous? Trustworthiness and authenticity in naturalistic evaluation. N Dir Eval. 1986;30(30):73-84. https:/doi.org/10.1002/ev.1427.

24. United Nations Programme on HIV/AIDS. UNAIDS 90-90-90. An ambitious treatment target to help end the AIDS epidemic by 2030. https:/www.unaids. org/sites/default/files/media_asset/90-90-90_en.pdf Accessed 28 August 2021.

25. Figueroa C, Johnson C, Verster A, Baggaley R. Attitudes and acceptability on HIV self-testing among key populations: a literature review. AIDS Behav. 2015;19:1949-65. https://doi.org/10.1007/s10461-015-1097-8.

26. Prem Kumar SG, Anil Kumar G, Poluru R, Schneider JA, Dandona L, Vemu L, et al. Contact with HIV prevention programmes \& willingness for new interventions among truckers in India. Indian J Med Res June. 2013;137:1061-71.

27. Indravudh PP, Sibanda EL, d'Elbée M, Kumwenda MK, Ringwald B, Maringwa $\mathrm{G}$, et al. I will choose when to test, where I want to test': investigating young people's preferences for HIV self-testing in Malawi and Zimbabwe. AIDS. 2017;31 Suppl 3(Suppl3):S203-12. https://doi.org/10.1097/QAD. 0000000000001516 PMID: 28665878; PMCID: PMC5497773.

28. Pai Pant N, Joshi R, Dongra S, Taksande B, Kalantri SP, Pai M, et al. Evaluation of diagnostic accuracy, feasibility and client preference for rapid oral fluid based diagnosis of HIV infection in rural India. PLOS ONE. 2007;2(4):e367. https://doi.org/10.1371/journal.pone.0000367.

29. Sarkar A, Mburu G, Shivkumar PV, Sharma P, Campbell F, Behera J, et al. Feasibility of supervised self-testing using an oral fluid-based HIV rapid testing method: a cross-sectional, mixed method study among pregnant women in rural India. J Int AIDS Soc. 2016;19(1):20993. https://doi.org/10.744 8/IAS.19.1.20993.

30. Njau B, Ostermann J, Brown D, Muhlbacher A, Reddy E, Thielman N. HIV testing preferences in Tanzania: a qualitative exploration of the importance of confidentiality, accessibility, and quality of service. BMC Public Health. 2014;14(1):838. https://doi.org/10.1186/1471-2458-14-838.

31. Lee VJ, Tan SC, Earnest A, Seong PS, Tan HH, Leo YS. User acceptability and feasibility of self-testing with HIV rapid tests. J Acquir Immune Defic Syndr. 2007;45(4):449-53. https://doi.org/10.1097/QAl.0b013e318095a3f3.

32. Woodford MR, Chakrapani V, Newman PA, Shunmugam M. Barriers and facilitators to voluntary HIV testing among communities at high risk of HIVexposure in Chennai, India. Glob Public Health. 2016;11(3):363-79. https://doi.org/10.1080/17441692.2015.1057757.

33. Rao A, Patil S, Aheibam S, Kshirsagar P, Hemade P, Panda S. Acceptability of HIV Oral Self-Test Among Men Having Sex With Men and Transgender Population: A Qualitative Investigation From Pune, India. Infect Dis (Auckl). 2020;13:1178633720962809. https://doi.org/10.1177/1178633720962809.

34. Chaturvedi S, Singh Z, Banerjee A, Khera A, Joshi RK, Dhrubajyoti D. Sexual Behaviour Among Long Distance Truck Drivers. Indian J Community Med. 2006;31(3):153-6.

35. Agrawal HK, Rao RS, Chandrashekar S, Coulter JB. Knowledge of and attitudes to HIV/AIDS of senior secondary school pupils and trainee teachers in Udupi District, Karnataka India. Ann Trop Paediatr. 1999;19(2):143-9. https://doi.org/10.1080/02724939992464.

36. Strauss M, George G, Lansdell E, Mantell JE, Govender K, Romo M, et al. HIV testing preferences among long distance truck drivers in Kenya: a discrete choice experiment. AIDS Care. 2018;30(1):72-80. https://doi.org/10.1080/ 09540121.2017.1367086.

37. Kelvin EA, Cheruvillil S, Christian S, Mantell JE, Milford C, Rambally-Greener L, et al. Choice in HIV testing: the acceptability and anticipated use of a selfadministered at-home oral HIV test among south Africans. Afr J AIDS Res. 2016; 15(2):99-108. pmid:27399040. https://doi.org/10.2989/16085906.2016.1189442.

38. Naik R, Tabana H, Doherty $T$, Zembe $W$, Jackson D. Client characteristics and acceptability of a home-based HIV counselling and testing intervention in rural South Africa. BMC Public Health. 2012;12(1):824. 23009202. https://doi. org/10.1186/1471-2458-12-824.
39. Hector J, Davies M-A, Dekker-Boersema J, Aly MM, Abdalad CCA, Langa EBR, et al. Acceptability and performance of a directly assisted oral HIV selftesting intervention in adolescents in rural Mozambique. PLoS One. 2018; 13(4):e0195391. https://doi.org/10.1371/journal.pone.0195391.

40. Joint United Nations Program on HIV/AIDS. Voluntary counselling and testing (VCT). UNAIDS technical update. Geneva: UNAIDS; 2000.

\section{Publisher's Note}

Springer Nature remains neutral with regard to jurisdictional claims in published maps and institutional affiliations.
Ready to submit your research? Choose BMC and benefit from:

- fast, convenient online submission

- thorough peer review by experienced researchers in your field

- rapid publication on acceptance

- support for research data, including large and complex data types

- gold Open Access which fosters wider collaboration and increased citations

- maximum visibility for your research: over $100 \mathrm{M}$ website views per year

At BMC, research is always in progress.

Learn more biomedcentral.com/submissions 